Article

\title{
Impact of Chitosan Molecular Weight and Attached Non-Interactive Chains on the Formation of $\alpha$-Lactalbumin Nanogel Particles
}

\author{
Juan Du, Young-Hee Cho *, Ryan Murphy and Owen Griffith Jones * \\ Department of Food Science, Purdue University, 745 Agriculture Mall Drive, West Lafayette, IN 47907, USA; \\ jdu4062@yahoo.com (J.D.); murph170@purdue.edu (R.M.) \\ * Correspondence: cho173@purdue.edu (Y.-H.C.); joneso@purdue.edu (O.G.J.); \\ Tel.: +1-765-494-1292 (Y.-H.C.); +1-765-496-7723 (O.G.J.)
}

Academic Editor: Gaio Paradossi

Received: 28 February 2017; Accepted: 20 April 2017; Published: 26 April 2017

\begin{abstract}
Thermal treatment of protein-polysaccharide complexes will form nanogel particles, wherein the polysaccharide controls nanogel formation by limiting protein aggregation. To determine the impact of the chitosan molecular weight and non-interactive chains on the formation of nanogels, mixtures of $\alpha$-lactalbumin were prepared with selectively-hydrolyzed chitosan containing covalently-attached polyethylene glycol chains (PEG) and heated near the protein's isoelectric point to induce formation of nanogels. Turbidity of heated mixtures indicated the formation of suspended aggregates, with greater values observed at higher $\mathrm{pH}$, without attached PEG, and among samples with $8.9 \mathrm{kDa}$ chitosan. Mixtures containing $113 \mathrm{kDa}$ chitosan-PEG formed precipitating aggregates above $\mathrm{pH} 5$, coinciding with a low-magnitude colloidal charge and average hydrodynamic radii $>400 \mathrm{~nm}$. All other tested mixtures were stable to precipitation and possessed average hydrodynamic radii $\sim 100 \mathrm{~nm}$, with atomic force microscopy showing homogeneous distributions of spherical nanogel aggregates. Over all of the tested conditions, attached PEG led to no additional significant changes in the size or morphology of nanogels formed from the protein and chitosan. While PEG may have interfered with the interactions between protein and the $113 \mathrm{kDa}$ chitosan, prompting greater aggregation and precipitation, PEG did not indicate any such interference for shorter chitosan chains.
\end{abstract}

Keywords: chitosan; $\alpha$-lactalbumin; complex; copolymer; polysaccharide; protein; poly(ethylene glycol); nanogel

\section{Introduction}

Colloidal structures can be utilized for many applications in food materials, such as controlled delivery of bioactive compounds, modification of textures, and stabilization of interfaces [1]. One option is to create gelled biopolymers that are physically, chemically, or enzymatically treated so that their ultimate size is on the colloidal scale $(100-10,000 \mathrm{~nm})$. For example, microparticulated whey protein is a comminuted protein gel with excellent application as a fat replacer [2]. Another route is to create nanogels and microgels formed by controlled aggregation of whey proteins, particularly by using heat treatment in highly controlled solution conditions so that the resulting aggregate particles have dimensions within the range of $100-1000 \mathrm{~nm}[3,4]$. These structures have been proposed as interfacial stabilizers or components of composite gels, where the physical properties of the nanogels can impact the total system [5].

In the past decade, it was found that nanogels could be formed by heat treatment of protein and polysaccharide mixtures. Specifically, experiments showed that interactions between whey protein and charged polysaccharides will limit thermal aggregation of the protein at $\mathrm{pH}$ values near the isoelectric 
$\mathrm{pH}$ [6]. Inhibiting thermal aggregation of the protein by electrostatic interactions with polysaccharide directly translates to control of the ultimate size of formed nanogels [7]. A variety of techniques have been utilized to further control the ultimate size of nanogels, such as by changing the charge of the polysaccharide [8], by reducing the debye screening length with ions [9,10], or by reducing the tendency for forming disulfide bonds via chemical agents [11].

Associative interactions between proteins and polysaccharides are typically driven by electrostatic interactions among oppositely-charged, ionized groups on each component [12]. Proteins and most polysaccharides possess weak acid or weak base functionalities so that their relative ionization is dependent upon the $\mathrm{pH}$ of the solution [12]. Furthermore, proteins contain both weak acid and weak bases on their surface, so that the net-charge of the protein surface is either negative or positive if it is above or below its isoelectric $\mathrm{pH}$, respectively. It has been shown that interactions between proteins and polycations will occur at $\mathrm{pH}$ values slightly below the protein's isoelectric point, as there are sufficient anionic residues on the protein surface to allow limited interactions with the polycations despite the presence of cationic residues [13]. At a given $\mathrm{pH}$, there will then be a driving force for associative interactions between a protein and a cationic polysaccharide based upon the number of anionic residues on the protein surface and the number of cationic charges on the polysaccharide, all of which is defined by the solution $\mathrm{pH}$ and the relative quantity of proteins and polysaccharides in the mixture [14]. Thus, it is important to define interactions based on the solution $\mathrm{pH}$ and quantities of protein and polysaccharide, the latter of which is typically represented by a protein-to-polysaccharide ratio $(r)$.

Associative interactions between polyelectrolytes in solution can also be impacted by the presence of non-interactive chains present on one of the polyelectrolytes, which is utilized in polymer research to create novel colloidal assemblies from copolymers [15]. Specifically, copolymers may be created with homogeneous chains of either charged or uncharged monomers as end-to-end 'blocks' or as "grafts" that are attached to the side of the main chain. Such copolymers have a tendency to associate with oppositely-charged polyelectrolytes, yet the presence of non-interactive segments forces the assembly to take on specific structural arrangements, such as spheres or cylinders [16]. In a recent study, the assembly of spherical structures was demonstrated from an association between protein and a block copolymer comprised of an anionic polysaccharide and poly(ethylene glycol) (PEG) [17]. Such interactive complexes should also be formed if the polysaccharide component is cationic, although this has not yet been explored. Furthermore, no studies have determined the influence of a non-interactive chain on the ability of a charged polysaccharide to change the tendency of the associative protein to aggregate or to form nanogels.

This study was then built upon two notions: (i) size of nanogels formed by heat treatment of protein-polysaccharide complexes is impacted by the degree of electrostatic association between the polysaccharide and protein, and (ii) interaction between a charged polysaccharide and protein is impacted by the covalent attachment of PEG to the polysaccharide. It logically followed that the size of nanogels formed from protein-polysaccharide complexes would be indirectly controlled by covalently attaching PEG to the polysaccharide. Formation and physical properties of nanogels were determined using the model protein $\alpha$-lactalbumin ( $\alpha$-lac) and the cationic polysaccharide chitosan $(\mathrm{CH})$, a poly(glucosamine) previously used to create protein-based nanogels by thermal treatment [18]. It was hypothesized that interactions between $\alpha$-lac and $\mathrm{CH}$, ultimately defining the size of nanogels formed by thermal treatment, would be controlled by the covalent attachment of PEG to $\mathrm{CH}$, the length of the $\mathrm{CH}$ chains (i.e., $\mathrm{M}_{\mathrm{w}(\mathrm{CH})}$ ), and the relative amount of $\mathrm{CH}$ chains in relation to the amount of protein $(r)$.

\section{Results and Discussion}

To determine the impact of the polysaccharide molecular weight and the presence of non-interactive polymer segments on the formation of nanogels, $\mathrm{CH}$ samples were prepared with average molecular weights of 113,76 , and $8.9 \mathrm{kDa}$ with or without covalently attached $5 \mathrm{kDa}$ 
polyethylene glycol chains (PEG), which would ultimately be utilized to prepare complexes with $\alpha$-lactalbumin $(\alpha-$ lac $)$ and form nanogels by thermal treatment. Complex formation between $\alpha$-lac and $\mathrm{CH}$ has been attributed to electrostatic interactions between negative charges on $\alpha$-lac and positive charges on $\mathrm{CH}$ [18]. Investigation of the $\zeta$-potential of $\alpha$-lac, $\mathrm{CH}$, and covalently-linked graft copolymers of $\alpha$-lac and $\mathrm{CH}$ (CHPEG) verified that all $\mathrm{CH}_{X X}$ and $\mathrm{CH}_{X X}$ PEG samples were positively charged across the $\mathrm{pH}$ range of 3.5 to 7.5 while $\alpha$-lac possessed a dominant positive charge between $\mathrm{pH} 3.5$ and 4.5 and a dominant negative charge at $\mathrm{pH} 5$ and above (Figure S1). There was no significant difference in the $\mathrm{pH}$ dependence of the electrical charge of $\mathrm{CH}_{X X} \mathrm{PEG}$ solutions when compared to $\mathrm{CH}_{X X}$ solutions, indicating that the relatively small degree of PEG substitution had little effect on the electrophoretic mobility of $\mathrm{CH}$. Furthermore, no significant differences in $\zeta$-potential values were noted between $\mathrm{CH}_{X X}$ samples or $\mathrm{CH}_{X X}$ PEG samples with different molecular weights. Therefore, one would expect similar driving forces for electrostatic interaction and subsequent complex formation between $\alpha$-lac and all of the $\mathrm{CH}_{X X}$ or $\mathrm{CH}_{X X} \mathrm{PEG}$ samples with increasing $\mathrm{pH}$ of mixed solutions.

Light scattering observations of mixed solutions at different $r$-values showed that significant interactions occurred between $\alpha$-lac and $\mathrm{CH}_{X X}$ or $\mathrm{CH}_{X X} \mathrm{PEG}$ as the $\mathrm{pH}$ was adjusted from $\mathrm{pH} 3.5$ to 4.3 (Figure S2). No significant differences were noted among the different samples, implying that the molecular weight, attachment of PEG chains, and even the $r$-value had no impact on the initial interactivity between positively-charged amine groups on chitosan and negatively-charged residues on the surface of $\alpha$-lac. A previous study also found evidence of interactions between $\alpha$-lac and $\mathrm{CH}$ above $\mathrm{pH} 4$, validating these observations [19]. Based upon these findings, mixtures of $\alpha$-lac and either $\mathrm{CH}_{X X}$ or $\mathrm{CH}_{X X}$ PEG were prepared at different $r$-values and adjusted to $\mathrm{pH} 4.3,4.8,5.3$, and 5.8, with the logic that the first $\mathrm{pH}$ represented a $\mathrm{pH}$ value where weak complexes formed and the other three $\mathrm{pH}$ values represented incremental increases of $0.5 \mathrm{pH}$ units. These mixtures were subsequently heated at $70^{\circ} \mathrm{C}$ for $20 \mathrm{~min}$ in a water bath to observe the potential formation of nanogels.

\subsection{Turbidity of Heated $\alpha$-lac/ $\mathrm{CH}_{X X}$ or $\mathrm{CH}_{X X} P E G$ Complexes}

Turbidity measurements are good means to examine the colloidal properties of protein aggregates and have been previously utilized to study nanogels formed by heat treatment of protein-polysaccharide complexes [7]. Accordingly, turbidity values of heated mixtures of $\alpha$-lac $/ \mathrm{CH}_{X X}$ or $\mathrm{CH}_{X X} \mathrm{PEG}$ samples were determined as a function of $r$-value at $\mathrm{pH} 4.3,4.8,5.3$, and 5.8 (Figure 1). In general, turbidity of heated mixtures increased with increasing $\mathrm{pH}$ and also with the $r$-value. The turbidity values of heated $\alpha$-lac $/ \mathrm{CH}_{X X}$ complexes were significantly greater than those of $\alpha$-lac/CHXXPG complexes of the same molecular weight, indicating the formation of aggregates with larger size and/or increased quantity. Heated mixtures with the lowest molecular weight $\mathrm{CH}\left(\mathrm{CH}_{8.9}\right.$ and $\mathrm{CH}_{8.9} \mathrm{PEG}$ ) were more turbid when compared to mixtures with larger molecular weight $\mathrm{CH}$ for both non-PEGylated and PEGylated samples. For example, the most turbid mixture after heating at $\mathrm{pH}$ 4.8 was formed among mixtures with $\mathrm{CH}_{8.9}$ and $r=10$ (Figure 1 and Figure S3). Turbidity consistently decreased a small amount among all samples after two weeks of storage, which could be attributed to gradual separation of large nanogels, dust, or bubbles (Table S1).

Reduced turbidity among heated $\alpha$-lac $/ \mathrm{CH}_{X X} \mathrm{PEG}$ complexes indicated that there was relatively less aggregation between $\alpha$-lac during thermal treatment with the incorporation of the PEG chain. Aggregation during heat treatment of protein-polysaccharide complexes has been paired with the relative interactivity and subsequent protective actions of the polysaccharide against aggregation [6]. It is unlikely that $\mathrm{CH}_{X X} \mathrm{PEG}$ reduced $\alpha$-lac aggregation by interacting more strongly with $\alpha$-lac, since covalent attachment of PEG typically increases the hydrophilicity of polymers and decreases interactivity with proteins [20]. Thus, the reduced aggregation of $\alpha$-lac implied that $\mathrm{CH}_{X X} \mathrm{PEG}$ provided an increased steric barrier with the hydrophilic PEG chains acting as a deterrent to protein-protein interactions during thermal treatment. 


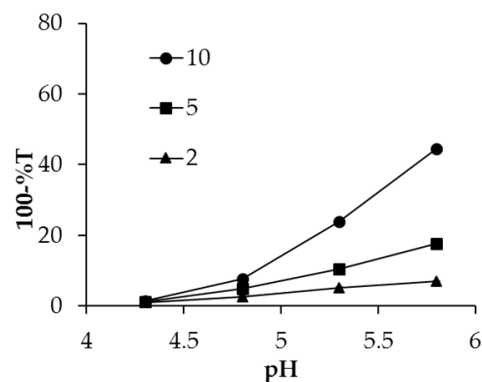

(a)

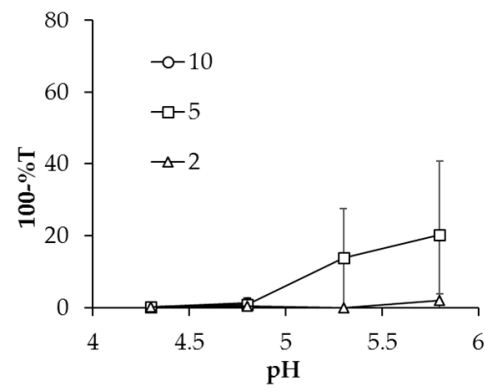

(d)

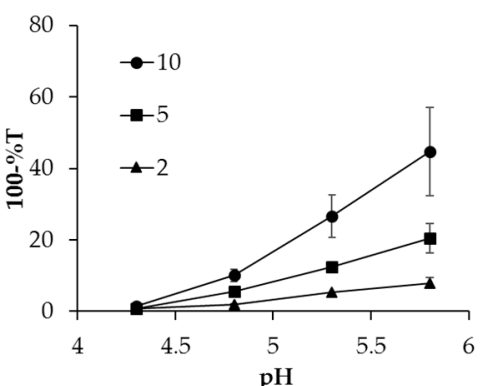

(b)

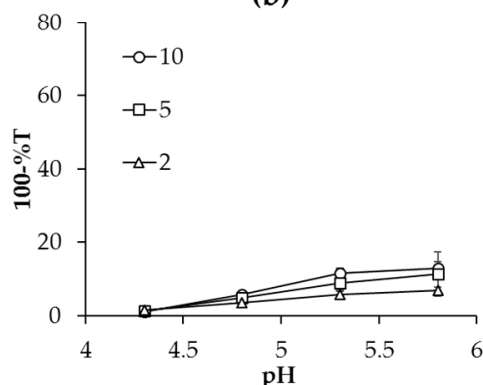

(e)

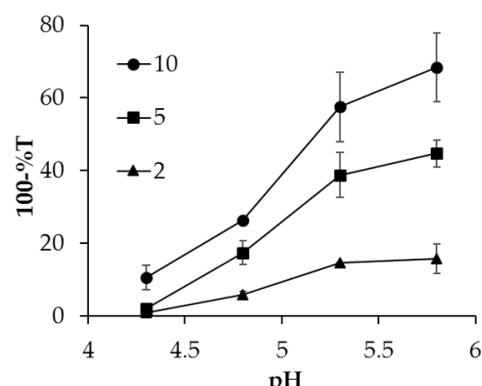

(c)

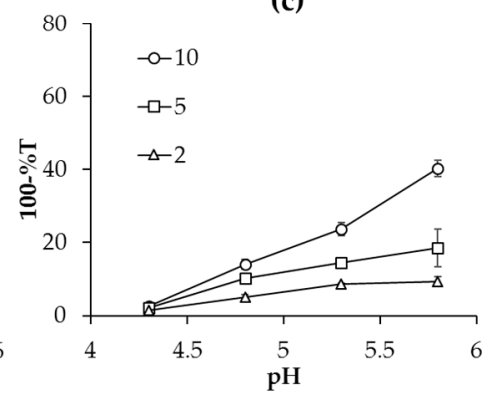

(f)

Figure 1. Effect of $\mathrm{pH}$ on turbidity of heated $\alpha$-lac complexes at different $r$-values for mixtures with (a) $\mathrm{CH}_{113}$, (b) $\mathrm{CH}_{76}$, (c) $\mathrm{CH}_{8.9}$, (d) $\mathrm{CH}_{113} \mathrm{PEG}$, (e) $\mathrm{CH}_{76} \mathrm{PEG}$, and (f) $\mathrm{CH}_{8.9}$ PEG. Note that datapoints are not shown for $\alpha-\mathrm{lac} / \mathrm{CH}_{113} \mathrm{PEG}$ for $r=10$ at $\mathrm{pH} 5.3$ and 5.8 due to formation of precipitates.

Low turbidity of heated mixtures at $\mathrm{pH} 4.3$ could be attributed to relatively less aggregation occurring in these conditions with little additional impact of the interactive $\mathrm{CH}_{X X}$ or $\mathrm{CH}_{X X} \mathrm{PEG}$. At $\mathrm{pH} 4.3, \alpha$-lac, $\mathrm{CH}_{X X}$, and $\mathrm{CH}_{X X}$ PEG all possessed a net-positive charge (Figure S1); so, while the complexes would have been relatively weak, aggregation of $\alpha$-lac during thermal treatment would also be relatively diminished. As the $\mathrm{pH}$ was increased, turbidity of the heated mixtures also increased because $\alpha$-lac had more propensity to aggregate in proximity to its isoelectric $\mathrm{pH}$. Turbidity increased further with increasing $\mathrm{pH}$ so that samples heated at $\mathrm{pH} 5.8$ were the most turbid for each type of complex. Samples of heated $\alpha$-lac without added $\mathrm{CH}_{X X}$ or $\mathrm{CH}_{X X}$ PEG formed large, precipitating aggregates at $\mathrm{pH} 4.8,5.3$, and 5.8. Thus, the increased turbidity with increasing $\mathrm{pH}$ could be attributed to either a greater tendency for $\alpha$-lac aggregation or to the promotion of aggregation by interaction with $\mathrm{CH}_{X x}$ or $\mathrm{CH}_{X X}$ PEG.

Above $\mathrm{pH} 4.8$, increased turbidity of heated mixtures with larger $r$-value could be attributed to the increased relative quantity of $\alpha$-lac that could be free to aggregate within the complexes. Samples with relatively more $\mathrm{CH}_{X X}$ or $\mathrm{CH}_{X X}$ PEG (i.e., $r=2$ ) would then be less prone to aggregation because the interactive $\mathrm{CH}_{X X}$ or $\mathrm{CH}_{X X} \mathrm{PEG}$ remains with the protein during heating and prevents the protein from fully aggregating, as has been hypothesized from previous observations of heated protein-polysaccharide complexes [6]. Greater turbidity noted among samples with the relatively short $\mathrm{CH}_{8.9}$ or $\mathrm{CH}_{8.9} \mathrm{PEG}$ could be attributed to relative inability of the shorter chain lengths to inhibit $\alpha$-lac aggregation because they conferred less of an electrosteric barrier when residing on the protein surface (Figure 1c,f). Surprisingly, this trend was not observed among heated $\alpha$-lac $/ \mathrm{CH}_{113} \mathrm{PEG}$ mixtures, where samples containing relatively more protein were more relatively more turbid $(r=5)$ or formed precipitates $(r=10)$ at $\mathrm{pH} 5.3$ and 5.8 (Figure 1d), which were the only sample mixtures where precipitation occurred. $\mathrm{CH}$ forms a rigid-rod conformation through inter-hydrophobic interactions and hydrogen bonding [21,22]. Therefore, the low molecular flexibility among the $\mathrm{CH}_{113}$ and $\mathrm{CH}_{113} \mathrm{PEG}$ samples would have limited their ability to interact effectively with single proteins because they would be less capable of coiling and conforming to the curvature of the $\alpha$-lac surfaces [23]. This factor did not appear to significantly impact aggregation among samples with $\mathrm{CH}_{113}$. However, in the case of $\mathrm{CH}_{113} \mathrm{PEG}$, the presence of covalently-attached PEG would have further restricted interactivity with 
$\alpha$-lac so that the protein was highly unprotected and free to form large, precipitating aggregates at high $\mathrm{pH}$.

\subsection{The $p H$ Dependence of $\zeta$-Potential of Heated $\alpha$-Lactalbumin $/ \mathrm{CH}_{X X}$ or $\mathrm{CH}_{X X} P E G$ Complexes}

In order to identify which set of heated mixtures would be more stable to further aggregation during storage, the electrical charge of heated mixtures with $\mathrm{CH}_{X X}$ or $\mathrm{CH}_{X X} \mathrm{PEG}$ was investigated as a function of $\mathrm{pH}$ and is shown for $r=10$ in Figure 2. $\zeta$-Potential of heated mixtures remained positive across the $\mathrm{pH}$ ranges studied, below and above $\mathrm{pI}$ of protein, indicating the remaining presence of positively-charged $\mathrm{CH}_{X X}$ or $\mathrm{CH}_{X X} \mathrm{PEG}$ on the aggregate surfaces. Magnitudes of $\zeta$-potential were greater at relatively higher molecular weight of $\mathrm{CH}\left(\mathrm{CH}_{113}\right.$ and $\left.\mathrm{CH}_{76}\right)$. There were no noticeable changes to the measured $\zeta$-potential of heated mixtures when comparing $\mathrm{CH}_{X X}$ (Figure 2a) and $\mathrm{CH}_{X X}$ PEG samples (Figure $2 \mathrm{~b}$ ), except for samples with $\mathrm{CH}_{113} \mathrm{PEG}$, indicating that the attached PEG chain did not impact the final charge signature among the aggregates.

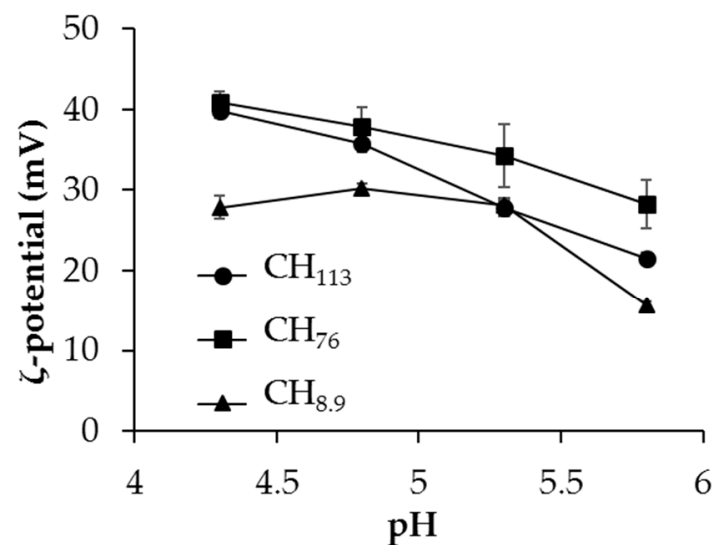

(a)

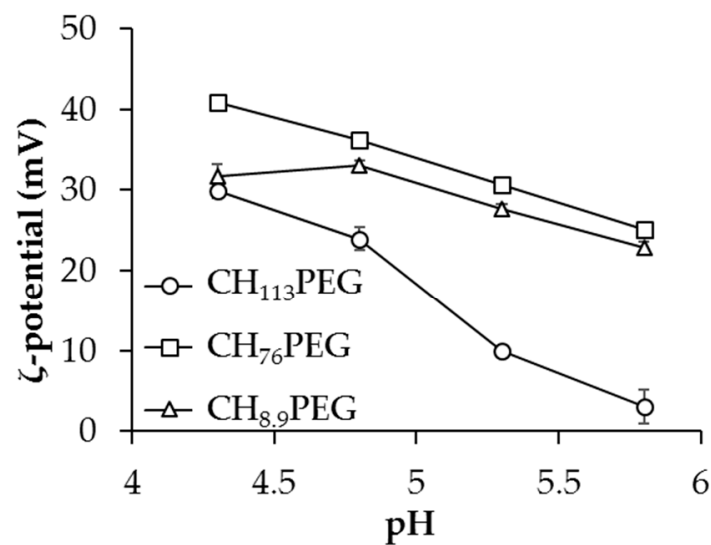

(b)

Figure 2. Effect of $\mathrm{pH}$ on the $\zeta$-potential of heated $\alpha$-lac mixtures $(r=10)$ with (a) $\mathrm{CH}_{\mathrm{XX}}$ and (b) $\mathrm{CH}_{X X} \mathrm{PEG}$.

The $\zeta$-potential values of all mixtures studied, except the unstable $\mathrm{CH}_{113}$ PEG samples, were above $+20 \mathrm{mV}$ across the studied $\mathrm{pH}$ range (Figure 2). This high magnitude of surface charge is typically associated with an increased colloidal stability due to strong electrostatic repulsions between colloidal particles. The results were also in agreement with the turbidity observations, which showed that all samples, except $\mathrm{CH}_{113} \mathrm{PEG}$, were stable to precipitation (Figure 1). There was a notable decrease in the magnitude of the positive charge among heated mixtures of $\alpha-\mathrm{lac}_{\mathrm{C}} / \mathrm{CH}_{113} \mathrm{PEG}$ when the $\mathrm{pH}$ increased, which could be attributed to a small electrophoretic mobility because the samples were in the form of larger aggregates, as discussed in the preceding section.

\subsection{Hydrodynamic Diameter and Morphology of Aggregates in Heated Mixtures}

Dynamic light scattering was utilized to investigate the hydrodynamic size of heated mixtures of $\alpha$-lac and $\mathrm{CH}_{X X}$ or $\mathrm{CH}_{X X}$ PEG to verify whether nanogel structures were created. Figure 3 demonstrates the effect of increasing $r$-value on average hydrodynamic radii of heated $\alpha-$ lac $/ \mathrm{CH}_{113}$ or $\mathrm{CH}_{113}$ PEG mixtures at $\mathrm{pH}$ values of $4.3,4.8,5.3$, and 5.8. Average hydrodynamic radii of all samples increased gradually as $\mathrm{pH}$ increased and were insensitive to $r$-value above $\mathrm{pH}$ 4.3. For $\mathrm{CH}_{113} \mathrm{PEG}$ samples, average hydrodynamic radii became larger $(>400 \mathrm{~nm})$ with increasing $\mathrm{pH}$, coinciding with a low-magnitude colloidal charge and the aforementioned formation of precipitates. All other tested mixtures were stable to precipitation and possessed average hydrodynamic radii on the order of $100 \mathrm{~nm}$, suggesting the formation of nanometer-scale aggregates. Based upon prior studies with similar components and procedures $[11,24,25]$, it was proposed that these aggregates are nanogels 
predominantly composed of $\alpha$-lac with $\mathrm{CH}_{X X}$ or $\mathrm{CH}_{X X} \mathrm{PEG}$ at the surface and potentially also within the internal regions of the nanogels. Surprisingly, apart from the precipitates observed among $\mathrm{CH}_{113} \mathrm{PEG}$ samples at higher $\mathrm{pH}$, there were no major differences in the observed hydrodynamic sizes of nanogels with changing molecular weight of $\mathrm{CH}$ (Figure S4).

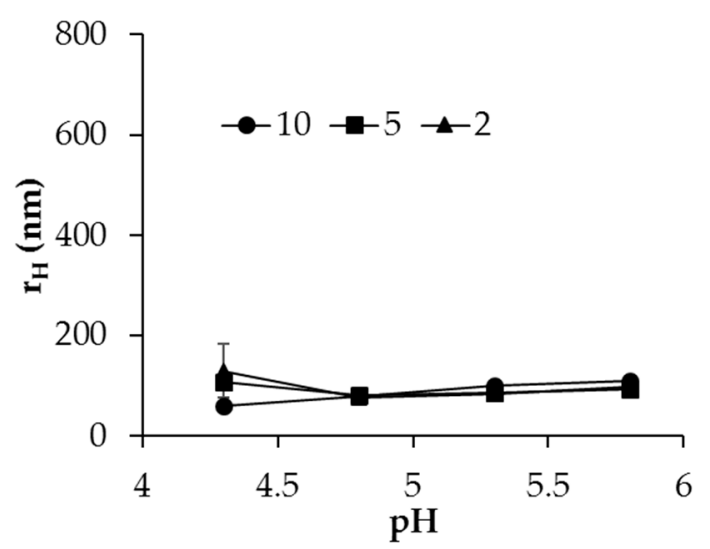

(a)

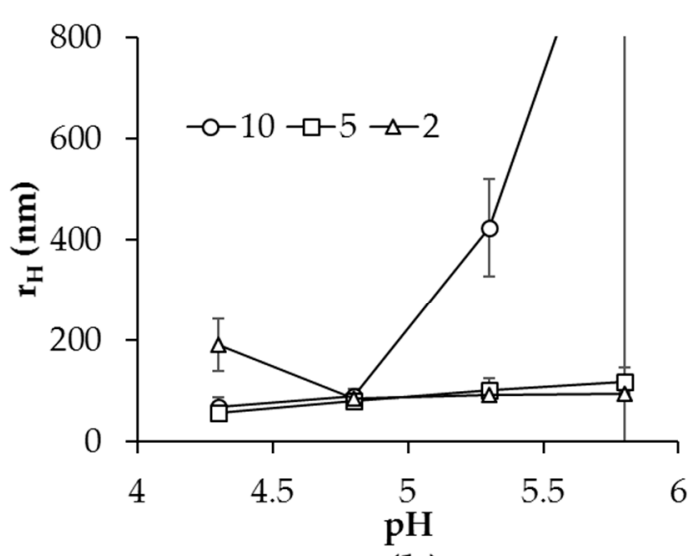

(b)

Figure 3. Effect of $\mathrm{pH}$ and $r$-value on hydrodynamic radii of heated $\alpha$-lac mixtures with (a) $\mathrm{CH}_{113}$ or (b) $\mathrm{CH}_{113}$ PEG.

Despite greater turbidity values among heated mixtures of higher $\mathrm{pH}$, larger $r$-value, and in samples without covalently-attached PEG (Figure 1), there were no significant changes in the detected hydrodynamic size of microgels above $\mathrm{pH} 4.3$ that did not form precipitates. Increased turbidity in the absence of chemical absorption could be attributed to either an increased size of colloidal objects, an increased refractive index, or an increase in the number of colloidal scatterers [26]. Thus, the lack of difference in detected hydrodynamic size suggested that all turbidity increases observed at increased $\mathrm{pH}$, larger $r$-value, and among mixtures with $\mathrm{CH}_{X X}$ samples compared to $\mathrm{CH}_{X X} \mathrm{PEG}$ were due to a greater number of formed aggregates.

At $\mathrm{pH} 4.3$, a few samples possessed a larger detected hydrodynamic diameter, but increased size was only consistently observed for $\mathrm{CH}_{113}$ PEG mixtures with $r=2$. It was not clear what caused the formation of nanogels with increased hydrodynamic sizes, although it could be potentially related to the lack of strong interactions between the components at $\mathrm{pH}$ 4.3. With weaker interactions, $\mathrm{CH}_{\mathrm{XX}}$ or $\mathrm{CH}_{X X} \mathrm{PEG}$ coils would be only modestly tethered at the nanogel surface so that they would spread further out into the solution and occupy a greater total volume.

In order to determine the morphology of nanogels formed from $\alpha$-lac $/ \mathrm{CH}_{113}$ or $\alpha-\mathrm{lac} / \mathrm{CH}_{113} \mathrm{PEG}$ $(r=2)$, mixtures heated at $\mathrm{pH} 4.8$ were characterized by atomic force microscopy (AFM) (Figure 4). Morphology of the aggregates was determined by atomic force microscopy to be spherical and of a fairly homogeneous size distribution. Edge-to-edge size of the particles observed by AFM were on the order of 50-100 nm while heights of the particles were on the order of 20-35 nanometers, which are significantly smaller than detected hydrodynamic diameters of the same samples. The relatively small sizes observed by AFM imaging in air can be attributed to the significant shrinkage of microgels during drying for sample preparation, which has been previously observed [10]. Observed particles from $\alpha$-lac/CH or $\alpha$-lac/CHPEG heated mixtures were all spherical structures with no noted differences in morphology. There were no significant differences in either the size or morphology of any of the tested samples, which agreed with measurements of the hydrodynamic radii by light scattering. 


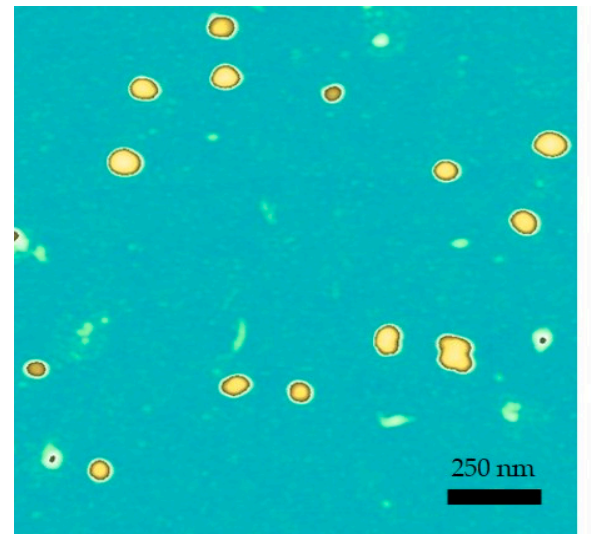

(a)

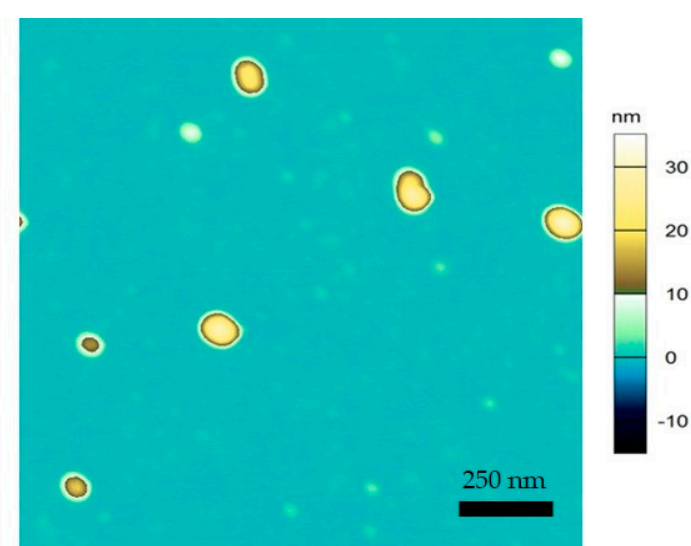

(b)

Figure 4. Images describing the topographical height of surface-deposited samples taken from heated $\alpha$-lac mixtures ( $r=2$, pH 4.8) with (a) $\mathrm{CH}_{113}$ or (b) $\mathrm{CH}_{113}$ PEG. Z-axis scale shown to right of (b).

\section{Conclusions}

Over all of the tested conditions, attached PEG led to no additional significant changes in the size or morphology of nanogels formed from the protein and $\mathrm{CH}$, regardless of the molecular weight of the $\mathrm{CH}$ chain or the relative amount of added protein. This directly refuted the hypothesis, leading to the conclusion that addition of a non-interactive PEG chain to $\mathrm{CH}$ has no significant impact on the size of nanogels formed by thermal treatment of associative complexes between $\mathrm{CH}$ and $\alpha$-lac. Reduced turbidity in mixtures heated with $\mathrm{CH}_{X X}$ PEG indicated that PEG may have interfered with the interactions between protein during aggregation, reducing the total number of aggregates formed without significantly altering the typical size of nanogels. Turbidity results also indicated that PEG could interfere with interactivity and stability of $\alpha$-lac with higher-molecular weight $\mathrm{CH}$ chains, prompting greater aggregation and precipitation. Apart from samples stabilized by the largest molecular weight $\mathrm{CH}_{X X} \mathrm{PEG}$, nanogels formed with both $\mathrm{CH}_{X X}$ or $\mathrm{CH}_{X X} \mathrm{PEG}$ were consistently small (hydrodynamic radius $\sim 100 \mathrm{~nm}$ ) and possessed a strong positive-charge in low-acid conditions. Altogether, these findings implied that the addition of covalently-attached PEG chains to chitosan provided no benefits in terms of greater microgel production or specific size/shape inducement during thermal treatment of the constituent protein. Utility of the microgels as delivery vehicles or components of composite materials would be dependent upon their size but also their tendency to expand or contract in different solvation conditions, so further investigations are required to understand whether the covalently-attached PEG chain will confer any additional physical properties to the nanogels that could be of use in biomedical applications.

\section{Materials and Methods}

\subsection{Materials}

High purity $\mathrm{CH}\left(M_{\mathrm{W}}=113 \mathrm{kDa}\right)$, monocarboxylated poly(ethylene glycol) (MPEG; $\left.M_{\mathrm{W}}=5 \mathrm{kDa}\right)$, 1-ethyl-3-(3-dimethylaminopropyl)carbodiimide (EDC), and $\mathrm{N}$-Hydroxysuccinimide (NHS) were purchased from Sigma-Aldrich (St. Louis, Saint Louis, MO, USA) and used as received. $\alpha$-Lactalbumin $(\alpha$-lac) was kindly donated by Davisco Food International from Le Sueur, MN. $\alpha$-lac was further purified by dialysis (MWCO $=3500 \mathrm{Da})$ against ultrapure water $(\sigma \geq 18 \mathrm{M} \Omega \cdot \mathrm{cm}$, Thermo Scientific, Waltham, MA, USA) for removal of minerals. Dialyzed $\alpha$-lac was lyophilized and kept at $-20^{\circ} \mathrm{C}$ as dry power before use. Chemicals including acetic acid, sodium hydroxide, sodium nitrite, sodium chloride, sodium acetate, imidazole, hydrochloride acid, and deuterium chloride were purchased from Sigma-Aldrich (St. Louis, Saint Louis, MO, USA). Deuterium oxide were purchased from Cambridge Isotope Laboratories, INC. (Andover, MA, USA). 


\subsection{Different Molecular Weight of CH Preparation and Characterization}

Portions of $\mathrm{CH}$ were depolymerized by oxidative degradation with $0.1 \mathrm{M}$ sodium nitrite based upon the method of Mao et al. [27]. In brief, $1 \%(w / w) \mathrm{CH}$ was prepared in $1 \%$ acetic acid aqueous solution and stirred overnight. Then, 27.79, 11.12, 4.45, 2.22, or $1.11 \mathrm{~mL}$ of $0.1 \mathrm{~N}$ sodium nitrite was added and allowed to react for $60 \mathrm{~min}$ at ambient temperature before neutralization with $1 \mathrm{~N}$ $\mathrm{NaOH}$. The precipitated $\mathrm{CH}$ was collected by centrifugation, washed with deionized water, and finally lyophilized.

Characterization of the molecular weight $\left(\mathrm{M}_{\mathrm{w}}\right)$ of $\mathrm{CH}$ samples before and after oxidative degradation was performed by Size Exclusion Chromatography (SEC). The measurement was done on an Agilent 1260 high performance liquid chromatography system equipped with a Sephadex 200/30 combination column, an Agilent 1260 ISO pump, and an Agilent 1260 Refractive Index Detector (Agilent Co., Santa Clara, CA, USA). CH samples were dissolved at $1 \mathrm{mg} / \mathrm{mL}$ overnight in a pH 4.5 solution of $100 \mathrm{mM} \mathrm{NaCl}$ and $20 \mathrm{mM}$ acetate and passed through a $0.45 \mu \mathrm{m}$ pore size syringe filter prior to injection. Two hydrolyzed samples corresponding to 4.45 and $2.22 \mathrm{~mL}$ of added nitrite solution, as well as the non-hydrolyzed $\mathrm{CH}$, were chosen for further testing, and their average molecular weights are reported in Table 1 . From here onward, samples are referred to as $\mathrm{CH}_{\mathbf{X X}}$, where $\mathrm{XX}$ refers to the determined molecular weight of each sample.

Table 1. Molecular weight, degree of deacetylation, and degree of substitution of $\mathrm{CH}_{X X}$ or $\mathrm{CH}_{X X} \mathrm{PEG}$ samples used in this study.

\begin{tabular}{ccccc}
\hline Sample & $\boldsymbol{M}_{\mathbf{W}} \mathbf{( k D a}^{\mathbf{1}}$ & DDA (\%) $^{\mathbf{2}}$ & Name Post-Modification & DS (\%) $^{\mathbf{3}}$ \\
\hline $\mathrm{CH}_{113}$ & 113 & $77.46 \pm 0.59$ & $\mathrm{CH}_{113}$ PEG & $6.78 \pm 0.94$ \\
$\mathrm{CH}_{76}$ & 76 & $83.37 \pm 0.44$ & $\mathrm{CH}_{76} \mathrm{PEG}$ & $8.14 \pm 1.41$ \\
$\mathrm{CH}_{8.9}$ & 8.9 & $77.20 \pm 2.54$ & $\mathrm{CH}_{8.9} \mathrm{PEG}$ & $9.94 \pm 1.58$ \\
\hline
\end{tabular}

${ }^{1}$ Weight-averaged molecular weight determined by size-exclusion chromatography as described in Section 4.2. 2 Degree of deacetylation determined by 1D Proton NMR as described in Section 4.3. ${ }^{3}$ Degree of substitution determined by 1D Proton NMR as described in Section 4.3.

\section{3. $C H_{X X} P E G$ Synthesis and Characterization}

Covalent attachment of PEG chains to the depolymerized and untreated $\mathrm{CH}_{X X}$ samples was performed by a facilitated amidation reaction, as described by Huh et al. [28]. Briefly, $\mathrm{CH}_{\mathrm{XX}}$ samples with different size were dissolved at a concentration of $10 \mathrm{mg} / \mathrm{mL}$ in $1 \%$ acetic acid solution and then diluted with the same volume of methanol. The coupling reactions between $\mathrm{CH}_{X X}$ and MPEG were achieved by using EDC and NHS as coupling agents at a $\mathrm{CH}_{X X}$ :MPEG:EDC:NHS weight-based ratio of 500:250:48:25, which were allowed to react at ambient temperature for $24 \mathrm{~h}$ and terminated by dialysis against ultrapure water for three days to remove coupling agents and unreacted MPEG. PEGylated $\mathrm{CH}\left(\mathrm{CH}_{X X} \mathrm{PEG}\right)$ samples in the retentate were lyophilized and stored dry at $-20{ }^{\circ} \mathrm{C}$ until used.

The degree of deacetylation (DDA) of $\mathrm{CH}_{X X}$ and the degree of substitution (DS) of PEG on $\mathrm{CH}_{X X} \mathrm{PEG}$ were determined through 1D Proton Nuclear Magnetic Resonance (NMR) spectra by using a $300 \mathrm{MHz}$ NMR (Varian, Inova 300, Palo Alto, CA, USA) with a $5 \mathrm{~mm}$ quadrupole-nucleus probe. All samples were dissolved by using $2 \%$ wt $\mathrm{DCl} / \mathrm{D}_{2} \mathrm{O}$ and then heated to $70{ }^{\circ} \mathrm{C}$ and cooled to room temperature right before the measurement. An example of the spectra for non-pegylated and pegylated samples of non-hydrolyzed $\mathrm{CH}_{113}$ is provided in Figure S5. Calculation of DDA was adopted from Hirai et al. [29] and Lavertu et al. [30], given as equation 1:

$$
\operatorname{DDA}(\%)=\left[1-\left(\frac{1}{3} \mathrm{H}_{\mathrm{ac}} \div \frac{1}{6} \mathrm{H}_{2 / 6}\right)\right] \times 100
$$

where $\mathrm{H}_{2 / 6}$ is the sum of integrated signals ascribed to protons at C-2 and C-6 positions (chemical shifted at 2.7 and $3.8 \mathrm{ppm}$ ) and $\mathrm{H}_{\mathrm{ac}}$ is the integrated signal ascribed to the acetyl group (1.6 ppm) 
based upon the assignations of Jeong and others [31]. Quantification of DS was performed based on the method of Huh et al. [28] as the ratio of the integrated signals ascribed to methylene units of PEG (3.19 ppm) and $\mathrm{CH}$ saccharide residues (2.92 ppm) in 1D Proton NMR spectra. A summary of the DDA and DS for each $\mathrm{CH}_{\mathrm{XX}}$ sample is provided in Table 1.

\subsection{Solution Preparation}

Buffer solution was prepared with $6 \mathrm{mM}$ acetate and $3 \mathrm{mM}$ imidazole at $\mathrm{pH}$ 3.5. Solution of $5 \mathrm{mg} / \mathrm{mL} \alpha$-lac was prepared by dissolving lyophilized $\alpha$-lac in buffer for $4 \mathrm{~h}$ at ambient temperature. Solutions of $1 \mathrm{mg} / \mathrm{mL} \mathrm{CHXX}$ or $\mathrm{CH}_{X X}$ PEG samples were prepared by dissolving lyophilized powders in buffer for $12 \mathrm{~h}$ at ambient temperature. Mixtures of $\alpha$-lac and either $\mathrm{CH}_{X X}$ or $\mathrm{CH}_{X X}$ PEG were prepared by mixing stock solutions with buffer at the desired proportion to achieve $\alpha$-lac: $\mathrm{CH}_{X X}$ ratios (r) of 10,5, or 2 with a constant combined $\alpha$-lac and $\mathrm{CH}_{\mathrm{XX}}$ content of $0.36 \mathrm{~g} / \mathrm{L}$ and a final volume of $15 \mathrm{~mL}$. This was achieved for mixtures with $\mathrm{CH}_{X X}$ PEG samples by identifying the contribution of PEG to the average molecular weight via the determined $D S$ values so that the amount of added weight of $\mathrm{CH}_{\mathrm{XX}} \mathrm{PEG}\left(W_{\mathrm{CHPEG}}\right)$ to achieve a specified weight of $\mathrm{CH}\left(W_{\mathrm{CH}}\right)$ (i.e., a consistent molar ratio) was found by equation 2 :

$$
W_{\mathrm{CHPEG}}=W_{\mathrm{CH}}\left(1+M_{\mathrm{W}(\mathrm{PEG})} \cdot \frac{(D S)}{M_{\mathrm{W}(\mathrm{res})}}\right)
$$

where $M_{\mathrm{W}(\mathrm{PEG})}$ is the molecular weight of PEG and $M_{\mathrm{W}(\mathrm{res})}$ is the molecular weight of an average $\mathrm{CH}$ residue taking into account the quantity of de-acetylated glucosamine residues $\left(M_{\mathrm{W}(\text { res })}=(D D A)\left(M_{\mathrm{W} \text { (glucosamine })}\right)+(1-D D A)\left(M_{\mathrm{W}(N-\text { acetyl glucosamine })}\right)\right.$. For each sample, the ratio $W_{\mathrm{CH}}: W_{\mathrm{CH}-\mathrm{PEG}}$ was found to be approximately 1:3 since DS and DDA were similar among the prepared $\mathrm{CH}$-PEG. Adjustment of the added weights in this fashion allowed direct comparison between mixtures with $\mathrm{CH}_{X X}$ and $\mathrm{CH}_{X X} P E G$, particularly since it was reasoned that only the $\mathrm{CH}$ component significantly contributes to interactivity with $\alpha$-lac.

Nanogels were prepared from mixtures based on an established method [6]. Briefly, adjustment of the $\mathrm{pH}$ for all solutions and mixtures was performed using 1 and $0.1 \mathrm{~N} \mathrm{NaOH}$ solutions. Aliquots were collected at desired $\mathrm{pH}$ values, placed in covered glass tubes, and stored at $4{ }^{\circ} \mathrm{C}$ until further analysis. Select samples were heated in a circulating water bath (Grant, Cambridge, UK) for $20 \mathrm{~min}$ at a temperature of $70{ }^{\circ} \mathrm{C}$. After heating, samples were submerged in cold water and stored under refrigeration until their characterization.

\subsection{Colloidal Sample Characterization}

Colloidal surface charge of aqueous suspensions were determined by laser Doppler micro-electrophoresis using a Zetasizer Nano ZS light scattering instrument (Malvern, Worcestershire, UK) at a scattering angle of $173^{\circ}$. Average colloidal charge is reported as $\zeta$-potential. Samples were measured at $25{ }^{\circ} \mathrm{C}$ in disposable plastic cuvettes.

Turbidity of aqueous suspensions as a function of $\mathrm{pH}$ was also measured by a UV-Vis spectrophotometer (DU 730 Beckman Coulter, Fullerton, CA, USA) at a wavelength of $450 \mathrm{~nm}$. The results of turbidity were presented as $100-T \%$, where $T$ is the light transmitted through the sample in the cuvette. Buffer of $6 \mathrm{mM}$ acetate, $3 \mathrm{mM}$ imidazole was used as reference blank.

Average hydrodynamic radii $\left(r_{\mathrm{H}}\right)$ of heated mixtures were determined by dynamic light scattering with an ALV-CGS3 light-scattering goniometer (ALV, Langen, Germany) at a scattering angle of 90 degrees. $r_{\mathrm{H}}$ reported in the figures were calculated from the $z$-average diffusion coefficients using the Stokes-Einstein equation, where diffusion coefficients were determined using the CONTIN algorithm. All samples were diluted in buffer until concentration dependence was no longer observed in order to eliminate multiple scattering effects.

Complex morphologies of selected samples were characterized with an MDP-3D atomic force microscope (Asylum Research, Santa Barbara, CA, USA) based upon an established method [11]. 
Samples were characterized in a dry state to reduce measurement noise and maximize surface attachment. Each sample was prepared by depositing $50 \mu \mathrm{L}$ of diluted aqueous suspension onto freshly-cleaved mica, drying it under a stream of filtered air, and storing it overnight in a desiccator. Topographical images were obtained using a silicon nitride cantilever tip with aluminum reflex coating, a nominal spring constant of $5 \mathrm{~N} / \mathrm{m}$, and a resonance frequency of $150 \mathrm{kHz}$.

\subsection{Statistical Treatment}

The results were presented as the average of duplicate or triplicate. Statistical significance was conducted by means of the student's $t$-test. Displayed error bars represent the standard deviation from independent sample measurements.

Supplementary Materials: The following are available online at http:/ /www.mdpi.com/2310-2861/3/2/14/s1, Figure S1: $\zeta$-potential of $\alpha$-lactalbumin, $\mathrm{CH}$, or $\mathrm{CH}$-PEG as a function of solution $\mathrm{pH}$; Figure S2: Intensity of scattered light at 90 degree scattering angle for mixtures of $\alpha$-lactalbumin and (a) $\mathrm{CH}_{76} \mathrm{PEG}$ or (b) $\mathrm{CH}_{76}$ at different $r$-values as a function of solution pH; Figure S3. Effect of $r$-value on turbidity of $\alpha$-lac complexes heated at $\mathrm{pH}$ 4.8 for mixtures with $\mathrm{CH}_{113}, \mathrm{CH}_{76}, \mathrm{CH}_{8.9}, \mathrm{CH}_{113} \mathrm{PEG}, \mathrm{CH}_{76} \mathrm{PEG}$, or $\mathrm{CH}_{8.9} \mathrm{PEG}$; Figure S4: Effect of $r$-value on hydrodynamic radii of detected colloids within heated mixtures of $\alpha$-lactalbumin and (a) $\mathrm{CH}$ or (b) CH-PEG of different molecular weight at $\mathrm{pH}$ 4.8; Figure S5: 1D Proton NMR spectra and assignations relevant to the chemical structures for (a) $\mathrm{CH}_{113}$ and (b) $\mathrm{CH}_{113} \mathrm{PEG}$ in $8 \% \mathrm{DCl} / \mathrm{D} 2 \mathrm{O}(v / v)$ at concentrations of $5 \mathrm{mg} / \mathrm{mL}$; Table S1: Turbidity of heated $\alpha$-lac $/ \mathrm{CH}_{76} \mathrm{PEG}$ mixtures at different $\mathrm{pH}$ and $r$-value 1 day after preparation and 14 days after preparation.

Acknowledgments: The authors would like to thank Anton Terekhov and Brad Reuhs for their assistance and advice during operation of NMR analyses. This project was made possible by funding from the Purdue Research Foundation and HATCH Act formula funds disbursed by the College of Agriculture at Purdue University.

Author Contributions: Owen Griffith Jones conceived and designed the experiments; Juan Du and Ryan Murphy performed the experiments; Juan Du, Young-Hee Cho, and Owen Griffith Jones analyzed the data; Young-Hee Cho and Owen Griffith Jones wrote the paper.

Conflicts of Interest: The authors declare no conflict of interest.

\section{References}

1. Jones, O.G.; McClements, D.J. Functional biopolymer particles: Design, fabrication, and applications. Compr. Rev. Food Sci. Food Saf. 2010, 9, 374-397. [CrossRef]

2. Barrantes, E.; Tamime, A.; Muir, D.; Sword, A. The effect of substitution of fat by microparticulate whey protein on the quality of set-type, natural yogurt. Int. J. Dairy Technol. 1994, 47, 61-68. [CrossRef]

3. Phan-Xuan, T.; Durand, D.; Nicolai, T.; Donato, L.; Schmitt, C.; Bovetto, L. On the crucial importance of the ph for the formation and self-stabilization of protein microgels and strands. Langmuir 2011, 27, 15092-15101. [CrossRef] [PubMed]

4. Sağlam, D.; Venema, P.; de Vries, R.; van Aelst, A.; van der Linden, E. Relation between gelation conditions and the physical properties of whey protein particles. Langmuir 2012, 28, 6551-6560. [CrossRef] [PubMed]

5. Nicolai, T. Formation and functionality of self-assembled whey protein microgels. Colloids Surf. B 2016, 137, 32-38. [CrossRef] [PubMed]

6. Jones, O.G.; McClements, D.J. Recent progress in biopolymer nanoparticle and microparticle formation by heat-treating electrostatic protein-polysaccharide complex es. Adv. Colloid Interface Sci. 2011, 167, 49-62. [CrossRef] [PubMed]

7. Jones, O.G.; Decker, E.A.; McClements, D.J. Formation of biopolymer particles by thermal treatment of beta-lactoglobulin-pectin complexes. Food Hydrocoll. 2009, 23, 1312-1321. [CrossRef]

8. Jones, O.G.; Lesmes, U.; Dubin, P.; McClements, D.J. Effect of polysaccharide charge on formation and properties of biopolymer nanoparticles created by heat treatment of beta-lactoglobulin-pectin complexes. Food Hydrocoll. 2010, 24, 374-383. [CrossRef]

9. Jones, O.G.; McClements, D.J. Biopolymer nanoparticles from heat-treated electrostatic protein-polysaccharide complex es: Factors affecting particle characteristics. J. Food Sci. 2010, 75, N36-N43. [CrossRef] [PubMed]

10. Hirt, S.; Jones, O.G.; Adijanto, M.; Gilbert, J. Influence of sulphate, chloride, and thiocyanate salts on formation of beta-lactoglobulin-pectin microgels. Food Chem. 2014, 164, 63-69. [CrossRef] [PubMed] 
11. Murphy, R.; Cho, Y.H.; Farkas, B.; Jones, O.G. Control of thermal fabrication and size of b-lactoglobulin-based microgels and their potential applications. J. Colloid Interface Sci. 2015, 447, 182-190. [CrossRef] [PubMed]

12. Schmitt, C.; Sanchez, C.; Desobry-Banon, S.; Hardy, J. Structure and technofunctional properties of protein-polysaccharide complex es: A review. Crit. Rev. Food Sci. Nutr. 1998, 38, 689-753. [CrossRef] [PubMed]

13. Park, J.M.; Muhoberac, B.B.; Dubin, P.L.; Xia, J.L. Effects of protein charge heterogeneity in protein-polyelectrolyte complexation. Macromolecules 1992, 25, 290-295. [CrossRef]

14. Mattison, K.W.; Dubin, P.L.; Brittain, I.J. Complex formation between bovine serum albumin and strong polyelectrolytes: Effect of polymer charge density. J. Phys. Chem. B 1998, 102, 3830-3836. [CrossRef]

15. Voets, I.K.; de Keizer, A.; Cohen Stuart, M.A. Complex coacervate core micelles. Adv. Colloid Interface Sci. 2009, 147-148, 300-318. [CrossRef] [PubMed]

16. Pergushov, D.V.; Müller, A.H.; Schacher, F.H. Micellar interpolyelectrolyte complexes. Chem. Soc. Rev. 2012, 41, 6888-6901. [CrossRef] [PubMed]

17. Du, J.; Reuhs, B.L.; Jones, O.G. Influence of pegylation on the ability of carboxymethyl-dextran to form complexes with $\alpha$-lactalbumin. Food Chem. 2016, 196, 853-859. [CrossRef] [PubMed]

18. Hong, Y.-H.; McClements, D.J. Formation of hydrogel particles by thermal treatment of $\beta$-lactoglobulin-chitosan complexes. J. Agric. Food Chem. 2007, 55, 5653-5660. [CrossRef] [PubMed]

19. Lee, A.-C.; Hong, Y.-H. Coacervate formation of $\alpha$-lactalbumin-chitosan and $\beta$-lactoglobulin-chitosan complexes. Food Res. Int. 2009, 42, 733-738. [CrossRef]

20. Zhang, M.; Desai, T.; Ferrari, M. Proteins and cells on peg immobilized silicon surfaces. Biomaterials 1998, 19, 953-960. [CrossRef]

21. De Souza, H.K.S.; Bai, G.; Gonçalves, M.D.P.; Bastos, M. Whey protein isolate-chitosan interactions: A calorimetric and spectroscopy study. Thermochim. Acta 2009, 495, 108-114. [CrossRef]

22. Halabalová, V.; Šimek, L. A study of the interaction between chitosan and poly(ethylene glycol) by viscosity method. Int. J. Polym. Anal. Charact. 2006, 11, 185-195. [CrossRef]

23. Cooper, C.L.; Goulding, A.; Kayitmazer, A.B.; Ulrich, S.; Stoll, S.; Turksen, S.; Yusa, S.-I.; Kumar, A.; Dubin, P.L. Effects of polyelectrolyte chain stiffness, charge mobility, and charge sequences on binding to proteins and micelles. Biomacromolecules 2006, 7, 1025-1035. [CrossRef] [PubMed]

24. Schmitt, C.; Moitzi, C.; Bovay, C.; Rouvet, M.; Bovetto, L.; Donato, L.; Leser, M.E.; Schurtenberger, P.; Stradner, A. Internal structure and colloidal behaviour of covalent whey protein microgels obtained by heat treatment. Soft Matter 2010, 6, 4876-4884. [CrossRef]

25. Jones, O.G.; Decker, E.A.; McClements, D.J. Comparison of protein-polysaccharide nanoparticle fabrication methods: Impact of biopolymer complexation before or after particle formation. J. Colloid Interface Sci. 2010, 344, 21-29. [CrossRef] [PubMed]

26. Nicolai, T. Food characterisation using scattering methods. In Understanding and Controlling the Microstructure of Complex Foods; Mcclements, D.J., Ed.; Woodhead Publishing: Cambridge, UK, 2007; pp. 288-310.

27. Mao, S.; Shuai, X.; Unger, F.; Simon, M.; Bi, D.; Kissel, T. The depolymerization of chitosan: Effects on physicochemical and biological properties. Int. J. Pharm. 2004, 281, 45-54. [CrossRef] [PubMed]

28. Huh, K.M.; Cho, Y.W.; Chung, H.; Kwon, I.C.; Jeong, S.Y.; Ooya, T.; Lee, W.K.; Sasaki, S.; Yui, N. Supramolecular hydrogel formation based on inclusion complexation between poly(ethylene glycol)-modified chitosan and $\alpha$-cyclodextrin. Macromol. Biosci. 2004, 4, 92-99. [CrossRef] [PubMed]

29. Hirai, A.; Odani, H.; Nakajima, A. Determination of degree of deacetylation of chitosan by $1 \mathrm{H}$ NMR spectroscopy. Polym. Bull. 1991, 26, 87-94. [CrossRef]

30. Lavertu, M.; Xia, Z.; Serreqi, A.N.; Berrada, M.; Rodrigues, A.; Wang, D.; Buschmann, M.D.; Gupta, A. A validated $1 \mathrm{H}$ NMR method for the determination of the degree of deacetylation of chitosan. J. Pharm. Biomed. Anal. 2003, 32, 1149-1158. [CrossRef]

31. Jeong, Y.-I.; Kim, D.-G.; Jang, M.-K.; Nah, J.-W. Preparation and spectroscopic characterization of methoxy poly(ethylene glycol)-grafted water-soluble chitosan. Carbohydr. Res. 2008, 343, 282-289. [CrossRef] [PubMed]

(C) 2017 by the authors. Licensee MDPI, Basel, Switzerland. This article is an open access article distributed under the terms and conditions of the Creative Commons Attribution (CC BY) license (http:/ / creativecommons.org/licenses/by/4.0/). 